\title{
研究速報
}

\section{低融点ろう材によるダイヤモンド砥粒固定ワイヤーソーの試作と これを用いた単結晶シリコンのスライス加エ}

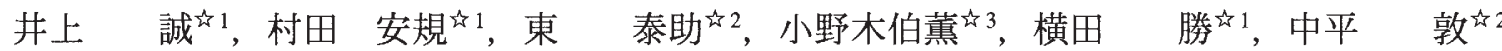 \\ 的1 侏中村超硬, $=593-8325$ 堺市西区鳳南町 5-682-8. \\ 的 2 大阪府立大学大学院工学研究科, $\bar{T} 599-8531$ 堺市中区学園町 1-1.
}

\section{Development of Brazed Diamond Abrasive Wire Saws for Slicing Single Crystal-Silicon}

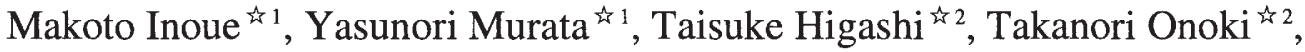 \\ Masaru Yokota ${ }^{\text {负1 }}$ and Atsushi Nakahira ${ }^{\text {is } 2}$ \\ is 1 Nakamura Choko CO.,LTD., 5-682-8 Ootori Minami-machi, Nishi-Ku, Sakai 593-8325, Japan. \\ ${ }^{2}{ }^{2}$ Graduate School of Engineering, Osaka Prefecture University, 1-1 Gakuen-cho, Naka-ku, Sakai 599-8531, Japan.
}

Received July 28, 2009

\section{SYNOPSIS}

Existing methods for slicing hard and brittle materials such as silicon use loose abrasives or fixed abrasive wire of which abrasives are adhered onto wire by resinoid bond or electroplating bond. Authors made an experiment to adhere abrasives onto high-tensile-strength SUS304 wire using low melting temperature brazing filler metal. The results were as follows.

1. Surface of diamond abrasives were modified by coating thin layers of $\mathrm{TiC}$ and $\mathrm{Ni}-\mathrm{P}$ followed by heat treatment at $1173 \mathrm{~K}$. Wettability with brazing filler metal and adhesive strength were improved.

2. By drawing SUS304 wire upward through vertically connected two crucibles of molten brazing filler metal and diamond abrasives, we successfully made the fixed abrasive diamond wire saw.

3. We converted a loose abrasive cutting machine into a fixed abrasive multi wire saw. Using this machine, we sliced single-crystal silicon and obtained desired results.

KEY WORDS

abrasive diamond particles, wire saw, brazing alloy, hard brittle materials, slice cutting

\section{1 緒言}

太陽光エネルギーを直接電気エネルギーに変換するデバイ スとしてシリコンウエハーがあり，エネルギー，環境，地球 温暖化への諸問題から世界的に関心が高まり，工業先進諸国 が競ってその生産, 高性能化, コス卜低減化等に努めている. 油性スラリーを用いた遊離砥粒方式 ${ }^{1,2)}$ が主流であったが, 材料費からスライス加工品に至るまでの製造コストが高くつ くこと, 廃液処理等に係る環境問題が無視できないなど幾多 の解決すべき課題が指摘されてきた．これらを解決する技法 として, 先ずレジンなどの高分子接合剤で $\mathrm{Al}_{2} \mathrm{O}_{3}$ より硬いダイ ヤモンドなどの超砥粒を固定化する技術が開発され ${ }^{3}$, 続いて 電気メッキによるダイヤモンド等の固定砥粒式ワイヤーソー4) とそれを用いた硬くて脆い材料のスライシング加工の実用化 がなされつつある.しかしこながらこれらの技法での大きな 問題点は，レジンでは砥粒の保持力が弱く、ソーワイヤーの スライシング寿命が短いこと, 電気メッキ法では長尺のワイ
ヤーソーの製造に時間がかかり，製造コストが高くつく問題 があった。

したがって本開発研究では高性能，長寿命，低コストを目 指して高抗張力の SUS304 細線に低融点万う材を用いてダイ ヤモンド砥粒を接合させる固定砥粒式ワイヤーソーを試作す るとともに，遊離砥粒式ワイヤーソー設備を固定砥粒式ワイ ヤーソーによるスライシング装置への改造を行い, 硬く脆い 材料である単結晶シリコンのスライシング加工を試み，太陽 光エネルギー一電気エネルギー変換用シリコンウエハー製造 の実用化への可能性を検討した.

\section{2 試料ならびに実験方法}

(1) ろう材ならびにろう付け温度

$873 \mathrm{~K}$ 以下でろう付け可能なろう材として筆者らが開発した $\mathrm{Ag}-\mathrm{Cu}-\mathrm{Sn}-\mathrm{Ni}$ 万う材 (液相線温度: $843 \mathrm{~K}$, 固相線温度: $788 \mathrm{~K}$ ) を採用した ${ }^{5)}$. ろう付け温度は $873 \mathrm{~K}$ とした。 
(2) 線材

ワイヤーソーに求められる主要な条件は高い張力に耐えう ることである.またろう付けによりダイヤモンド砥粒を固定 化させるには線材の強度がろう付け時の加熱により低下しな いことも重要な条件となる.ここで取り上げた素線はろう付 け性を高めるためにNi被覆を施したオーステナイト系ステン レス鋼の SUS304 であり，線径は $0.16 \mathrm{~mm}$ である.

(3) ダイヤモンド砥粒の表面改質

ダイヤモンドをろう付けによって固定させる方法として， Tiを含む活性ろう材を使用するのが一般的であるがの, $1173 \mathrm{~K}$ 以上の真空条件下でのろう付け作業となり，ワイヤー素材の

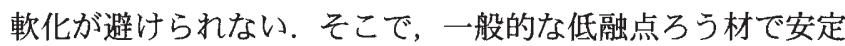
的なろう付けが可能となるように，ダイヤモンドの表面に多 層コーテイングを行った.ダイヤモンド砥粒の表面にまず $\mathrm{TiC}$ 皮膜を施し7), さらにその上に無電解メッキ法による Ni-P 合金皮膜を施した ${ }^{8)}$.ダイヤモンド砥粒表面の各多層膜界面で の接合強度を高めるために, 真空中において $1173 \mathrm{~K} て ゙ 900 \mathrm{~s} の$ 熱処理を施した。

(4) ダイヤモンド砥粒の SUS304 細線へのろう付け

著者らが開発したルツボ法 ${ }^{9,10)}$ を採用した。すなわち，2個 の黒鉛製るつぼの底部に直径が約 $0.2 \mathrm{~mm}$ の穴を穿ち, 下部の るつぼにろう材, 上部のるつぼにダイヤモンド砥粒を挿入し, るつぼの底部に穿った細孔に SUS304 線を下方から上方に連 続走行させてダイヤモンドのろう付けを行った。なお，雰囲 気は $\mathrm{N}_{2}-5 \% \mathrm{H}_{2}$ の還元性雾囲気である. またろう付けのための 加熱温度は $873 \mathrm{~K}$ とし，高周波加熱を行った。

(5)試作ダイヤモンド砥粒固定ワイヤーソーのスライス加工試験 硬くて脆い材料として単結晶シリコンインゴット(寸法: 25 $\left.\times 25 \times 50 \mathrm{~mm}^{3}\right)$ について試作マルチワイヤーソーのスライス加 工試験を行った。採用したスライス加工設備は遊離砥粒式ス ライス加工機(侏夕カトリ製)を固定砥粒式ワイヤーソーに適 用できるように一部を改造した.

\section{3 実験結果ならびに考察}

3.1 ソーワイヤーの加熱による硬さ変化

ソーワイヤーへのダイヤモンド砥粒の固定化にはろう付け による熱処理が伴う。この熱処理によるソーワイヤーの軟化
の程度を硬さ試験の結果により評価した，本研究ではろう付 け温度を $873 \mathrm{~K}$ とし，ソーワイヤーとして SUS304 (A または B)を採用したが, 他に候補として挙げられるSUS630, SUS631 およびピアノ線についても加熱温度と硬さの関係を測定した. Fig.1 に示すように, SUS304 (AおよびB)の 873K における硬 さは他の線材に対して軟化の程度は少なく，素材の硬さに対 して $10 \%$ 以下の硬さの低下に留まることが明らかになった. 3.2 ダイヤモンド砥粒の多層メッキによる表面改質

ダイヤモンド素材の表面改質によるろう材との接合性を改 善する必要がある. そのために, 先ずダイヤモンドにTiCコー テイングを施し，さらにその上に TiCとの結合性が良好な $\mathrm{Ni}$-Pを無電解法でメッキを上乗せした．TiCコーテイング量 はコーテイングされたダイヤモンド粒全体質量の5 mass\%に, また Ni-P メッキ量は同じく 50 mass\% とした．表面改質前の ダイヤモンド粒, $\mathrm{TiC}$ 被覆ダイヤモンド粒およびその上にさ らに Ni-P メッキを施したダイヤモンド粒の SEM 写真を Fig.2 に示す.それぞれの粒子ともに平滑な表面状態を示している.

ダイヤモンド粒子に TiCと Ni-P被覆を施しただけでは各層 間の強度は高くないのでこれを改善するために熱処理をする 必要がある. 予備実験の結果から熱処理の温度を $1173 \mathrm{~K}$, 保 持時間を $900 \mathrm{~s}$ とした. 加熱の䨌囲気は真空中である.

TiCならびに Ni-P を被覆したダイヤモンド粒子を Fig.3 (a) に示す．またこの粒子を上記の条件で加熱処理した粒子の SEM 写真を Fig.3 (b) に示す. 熱処理によってもダイヤモンド

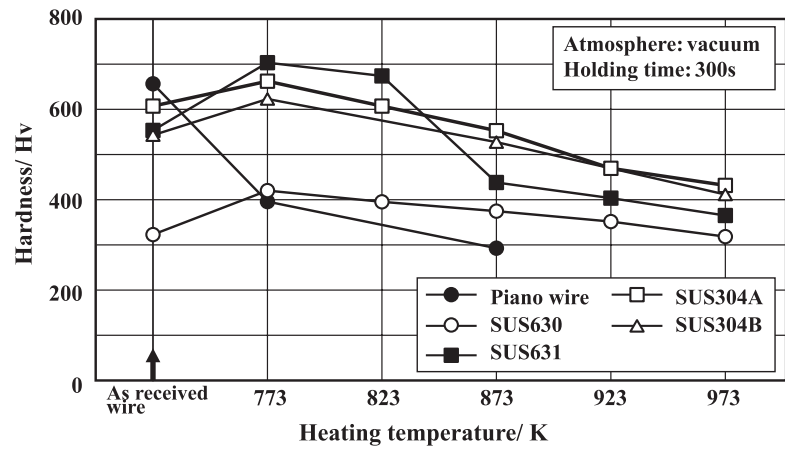

Fig.1 Relation between hardness and heating temperature for typical high tension fine wires; heating atmosphere: vacuum, heating time: $300 \mathrm{~s}$.
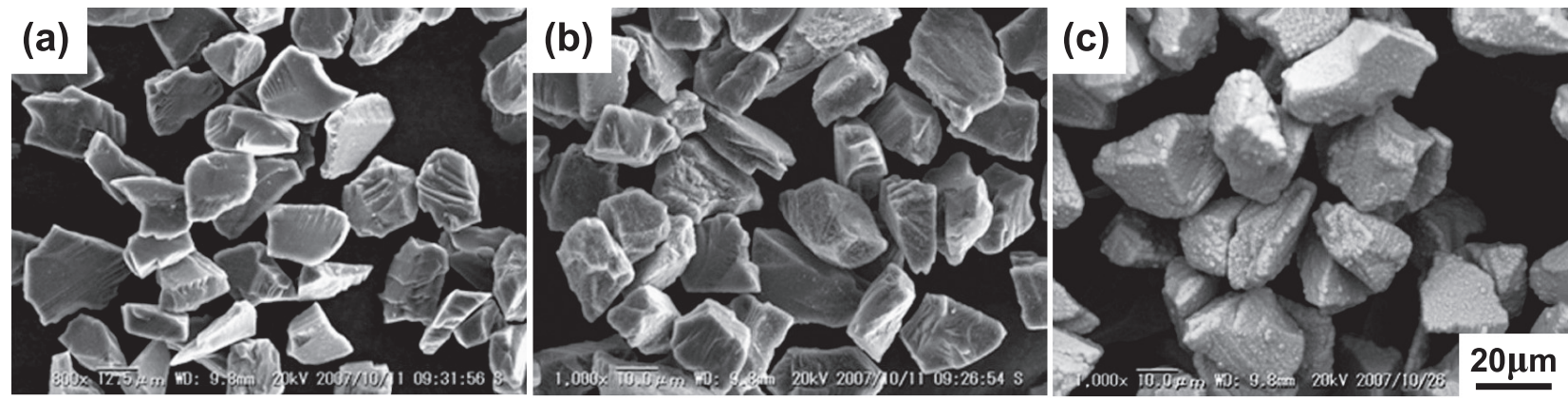

Fig.2 SEM images of as-received (a), TiC coated (b) and additionally Ni-P coated (c) diamond fine particles (Original particle size of diamonds; 20 to $30 \mu \mathrm{m}$ in diameter). 

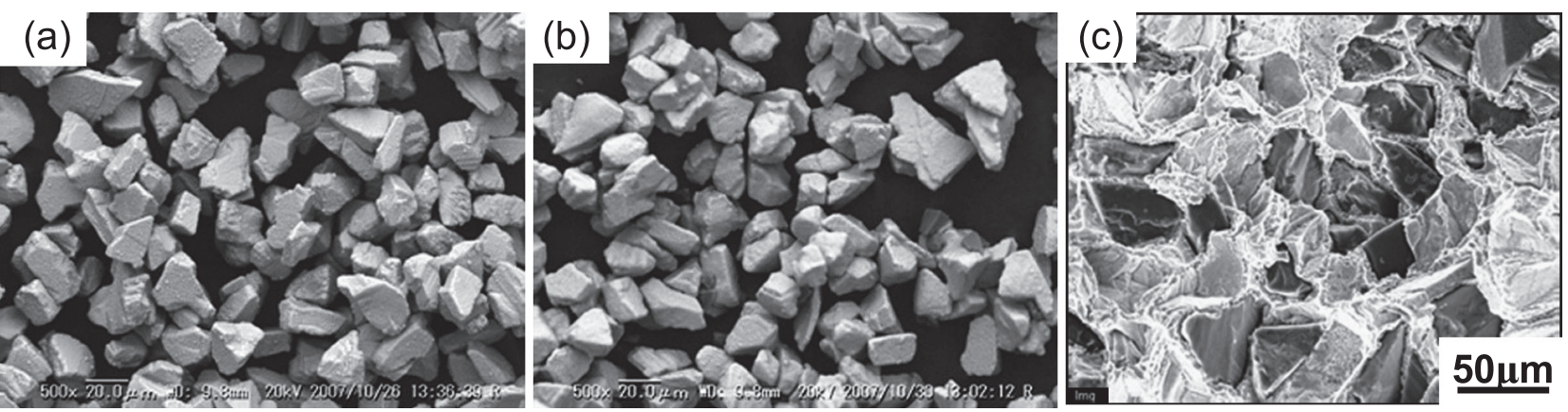

Fig.3 SEM images of TiC and then Ni-P coated (a) subsequently heat treated diamond fine particles at $1123 \mathrm{~K}$ for $1.8 \mathrm{Ks}$ in vacuum (b), and fracture surface of sintered compact of multi-coated diamond powders (c).

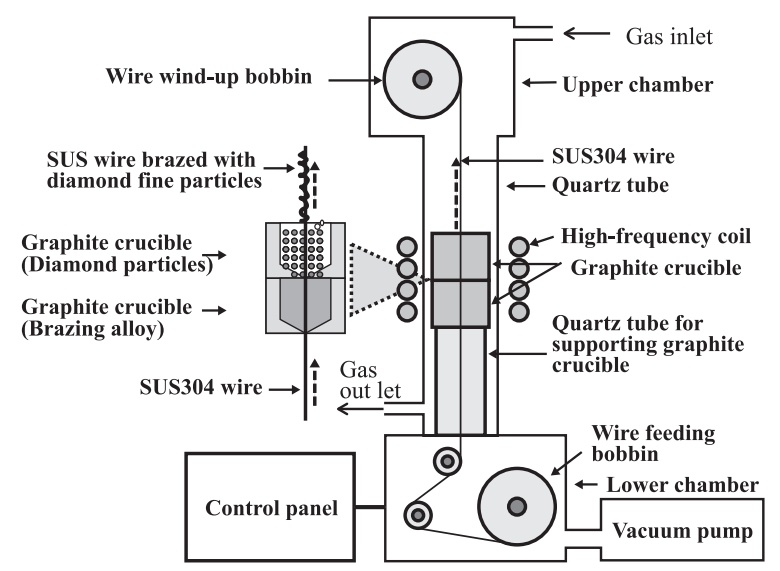

Fig.4 Schematic diagram for manufacturing equipment of diamond brazed wire saw.

粒子の表面は良好な平滑状態を示している.

ダイヤモンド粒子, TiC膜ならびに Ni-Pメッキを施した各 層間の熱処理による結合強度を評価する必要がある。これを 目的として, Ni-Pにまで表面被覆したダイヤモンド粒子を粉 末状のろう材とともに黒鈴製のダイスにより圧力 $0.5 \mathrm{~Pa}, 773 \mathrm{~K}$, $300 \mathrm{~s}$ の条件下でホットプレッシングを行い，ろう材中にダイ ヤモンド粒子を分散させた試料を作製した。これを曲げによ り破断させ, その破断面をSEM観察した. その結果をFig.3(c) に示す．写真から明らかなように，曲げ応力によりダイヤモ ンド粒子はその内部で破断し,ダイヤモンドとろう材との結 合が強力であることを示している.

3.3 るつぼ法によるSUS304細線へのダイヤモンド砥粒の連続 ろう付计装置の試作

試作した連続ろう付け装置の概略図をFig.4に示す. まず真 空ポンプにより装置の内部を排気した後 $\mathrm{Ni}+5 \% \mathrm{H}_{2}$ ガスに置 換し，ろう付けを還元性雾囲気で行った．石英管内部に設置 された2段の黒鈴製るつぼの底部に直径が約 $0.2 \mathrm{~mm}$ の穴を穿 ち，下段のるつぼにろう材を，上段のるつぼにダイヤモンド 砥粒を挿入し,その中にSUS304細線を走行させ連続してろう 付けとダイヤモンドの接合を行った.るつぼの加熱は石英管 外部からの高周波誘導法によった。ここで得られた低融点ろ

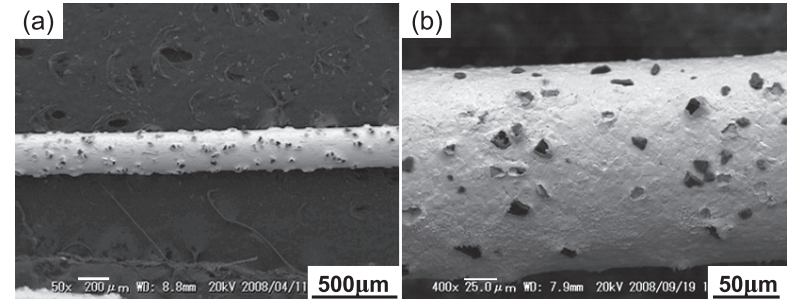

Fig.5 Photograph of manufacturing equipment of diamond brazed wire saw.

Table 1 Materials and experimental conditions for slice cutting of mono-crystalline silicon ingot.

\begin{tabular}{|l|c|}
\hline Size of mono-crystalline silicon ingot & $25 \times 25 \times 50 \mathrm{~mm}^{2}$ \\
\hline Material of wire & SUS304 \\
\hline Daimeter of wire & $\phi 0.16 \mathrm{~mm}$ \\
\hline Material of brazing alloy & Ag-Cu-Sn-Ni \\
\hline Diameter of diamond particles & $20-30 \mu \mathrm{m}$ \\
\hline Temperature of brazing & $873 \mathrm{~K}$ \\
\hline Feeding rate of wire & $300 \mathrm{~m} / \mathrm{min}$ \\
\hline Feeding mode & Reciprocate \\
\hline Winding number of multi-wire saw & 50 \\
\hline Length of wire used & $50 \mathrm{~m}$ \\
\hline Tension of wire & $18 \mathrm{~N}$ \\
\hline Rate of slice cutting & $0.25 \mathrm{~mm} / \mathrm{min}$ \\
\hline
\end{tabular}

う材によるダイヤモンド砥粒固定式ワイヤーソーのSEMによ る表面写真の一例をFig.5に示す.万う付けされたダイヤモン ド砥粒の分布状態の制御を含むこれら一連の詳細な説明は別 に述べてある ${ }^{9,10)}$.

3.4 試作ワイヤーソーを用いた単結晶シリコンのスライス加工 試験

本開発研究で得られた低融点ろう材によるダイヤモンド砥 粒固定式ワイヤーソーを使用して, 幅 $50 \mathrm{~mm}$, 高さおよび奥 行きがそれぞれ $25 \mathrm{~mm}$ の単結晶シリコンインゴットのスライ シング加工を試みた。加工条件は Table 1 に示した通りであ 


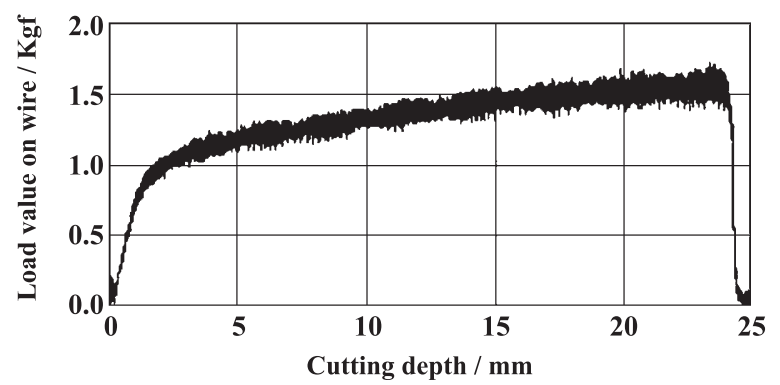

Fig.6 SEM images of diamond brazed SUS304 wire saw; the size of wire diameter is $160 \mu \mathrm{m}$.

る. スライシング加工時におけるシリコンインゴットにかか る荷重とスライシング深さの関係はFig.6に示すように, スラ イシング染さが増すにつれてシリコンインゴットへの荷重, すなわちりーワイヤーへの張力付加はわずかに増加する傾向 を示すが, 荷重值は加工の初期に $1 \mathrm{kgf}$, 終盤で $1.5 \mathrm{kgf}$ と大き な荷重がかかることなく単結晶シリコンのスライシング加工 に成功した. ここではマルチワイヤーソーとして同時に50枚 のシリコンのスライシングンを行ったが，そのうちの 1 枚を Fig.7の写真で示した.

太陽電池用のシリコンウエハーとしての品質評価には切断 面の平滑度が重要であり,これを保証する手段として安定した ワイヤーソーの製造とシリコン切断設備の確立化が残されて おり今後実用化に向けて検討と実践を進めて行く予定である.

\section{4 結 言}

試作した低融点ろう材によるダイヤモンド砥粒固定式ワイ ヤーソーによる単結晶シリコンインゴットのスライシング加 工を行った．得られた結果は次の通りである.

(1) ダイヤモンド砥粒に TiC, Ni-P 被覆した後, $1173 \mathrm{~K}, 900 \mathrm{~s}$ での熱処理によりろう材との濡れ性, 接着強度が良好な表 面改質されたダイヤモンド砥粒を得ることができた.

(2)万う材とダイヤモンド砥粒をそれぞれ挿入した2段のるつ ぼにSUS304細線を通すことにより連続したダイヤモンド 砤粒固定ソーワイヤーの試作に成功した.

(3)遊離砥粒式切削加工機器を固定砥粒式マルチワイヤーソー 用に改造し,本研究で得られたワイヤーソーを使用して単 結晶シリコンのスライシング加工を行い, 所期の目的に適 う期待された結果が得られた。

\section{文献}

1) T. Watanabe and M. Kojima: "Study of quartz crystal slicing

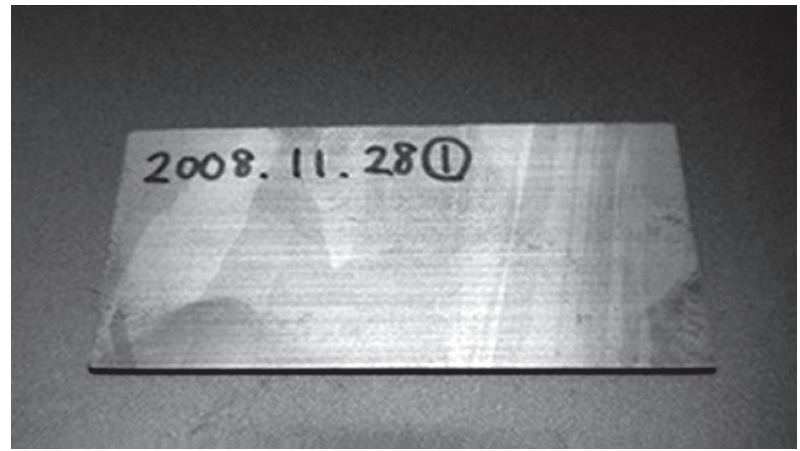

Fig.7 Relation between load value on wire and cutting depth for slice cutting of mono-crystalline silicon ingot.

technology by using multi wire saw", Technical report of IEICE. EA, 100(581)35-42.

2) K. Suzuki, S. Aoyama, and K. Yasuoka: "Cutting mechanism of muti wire saw", http://www.shinano-sic.co.jp/pdf/ r_d_wiresaw.pdf.

3) M. Nakai, H. Ogawa, M. Yamanaka, N. Urakawa, and M. Miyake: "Cutting efficiency of wire saw fixed with diamond abrasive fine particles", Collected papers of annual meeting, Japan Society for Precision Engineering, 2002(2)527.

4) K. Ishikawa, H. Suwabe, K. Kanayama, M. Makino, and H. Yoshida: "Study on Machining Characteristics of Wire Tool with Electrodeposited Diamond Grains", Transactions of the Japan Society of Mechanical Engineers C, 60(573)(1994)18151820.

5) T.e Higashi, T. Onoki, A. Nakahira, M. Inoue, M. Yokota, and Y. Murata: "Mechanical properties and low temperature brazing characteristics of Ag-Cu-Sn alloys", Abstracts of Spring Meeting of JSPM, (2009) 212.

6) O. Kamiya, T. Uchida, T. Kimura, and T. Ishikawa: "Resource saving type micro wire saw connected diamond with metals", Report of research, Faculty of engineering and Resource Science, Akita University, 23(2002)41-47.

7) N. Koura and N. Yoneda: "TiC Coating on Steels from the Molten Salts Bath by Electroless Technigue", The Journal of the Metal Finishing Society of Japan, 29(2) (1978)94-96

8) S. Ishibasi, ed. by Surface Finishing Society of Japan: "Mudenkai mekki", Asakura publishing Co.,Ltd., (1968)67.

9) Y. Murata and M. Inoue: "Koukai tokkyo kouhou (A), Tokkai", 2006-123024.

10) Y. Murata: "Koukai tokkyo kouhou (A), Tokkai", 2008-221406. 